\title{
Outbreak of Ornithosis
}

\author{
P. K. M. BARRETT,* M.B., M.R.C.P. ; M. J. GREENBERG, $†$ M.A., M.B., M.R.C.P.
}

Brit. med. F., 1966, 2, 206-207

Human illness resulting from a disease of birds has been recognized for over 80 years, and it is probable that this association was first recorded by Jurgesson in 1874 (Westwood, 1953).

In 1892 a major outbreak occurred in Paris following the shipment of 500 parrots from Buenos Aires. Three hundred of these birds died, and of 48 human contacts who developed pneumonia 16 died (Westwood, 1953 ; Leachman and Yow, 1958).

Sporadic outbreaks were described on the Continent and in the U.S.A. during the next 20 years, but it was not until the great pandemic of 1929 that world-wide interest was aroused and a search for the causative organism led to the discovery of the virus (Bedson, Western, and Simpson, 1930). 'This major outbreak followed an epidemic of psittacosis among the parrot population in the Argentine, and, as a result of the unrestricted trade in pet birds at the time, human disease occurred in many countries, including England, Austria, France, Czechoslovakia, Germany, the Netherlands, Brazil, Denmark, Switzerland, Japan, and the U.S.A. At least 400 human cases occurred, with a mortality rate of 35 to $40 \%$ (Westwood, 1953 ; Leachman and Yow, 1958).

Since this episode, as a result of legislation banning the importation of parrots, there have been no explosive outbreaks of this nature, but sporadic outbreaks have continued to be reported. In Louisiana in 1942 a particularly virulent strain caused illness in 19 people, of whom 8 died, and it was at this time that human-to-human transmission was first shown to occur (Olson and Larson, 1944 ; Olson and Treuting, 1944).

\section{Present Outbreak}

We now describe a minor epidemic which occurred in the Cambridge area in 1964, during which 29 cases of ornithosis attended one chest clinic.

Case 1.-A man aged 55 developed an unproductive cough, sore throat, headache, and left chest pain in January. He consulted his doctor, who found an impaired note at the left base and occasional basal rhonchi on the right side. He later developed an impaired note and basal crepitations on both sides. A few days later an urticarial rash developed on the hands and forearms. $\mathrm{He}$ was given a short course of chloramphenicol followed by a course of tetracycline, and serum taken for complement-fixation tests at this time showed a titre of less than 1 in 8 to psittacosis/lymphogranuloma venereum (L.G.V.). He appeared to respond to this treatment, and when seen at the chest clinic early in March there were no abnormal signs and the chest $x$-ray film was clear. However, the serum now showed a positive titre to psittacosis/L.G.V. of 1 in 256 . He returned to work, but two weeks later relapsed with right pleuritic pain, fever, muscular aches, and cough productive of yellowish sputum which was blood-stained. Crepitations and a right pleural rub were heard, and a chest film showed bilateral basal shadowing with filling-in of the costophrenic angles. He responded slowly to further treatment with tetracycline, and was unfit for work for nearly three months.

This patient kept racing-pigeons and stated that one of his birds had become ill three weeks before he first developed symptoms. The whole of his flock of 40 pigeons was sacrificed,

* Senior Registrar, Cambridge Chest Clinic.

t Consultant Chest Physician, Cambridge Chest Clinic. and 35 of these showed evidence of psittacosis on serological examination.

Case 2.-A 50-year-old female cowherd had an influenzal illness at the end of March, with fever, cough, and blood-stained sputum. Crepitations were heard at her right base, but the chest film was clear. She responded well to treatment with tetracycline. The complement-fixation tests to psittacosis/L.G.V. were positive 1 in 64, and two weeks later had fallen to 1 in 16 .

Case 3.-A son of the above patient (Case 2) had a similar illness at the same time as his mother. His chest film showed a "ground-glass" opacity in the left mid-zone, but no adventitious sounds were detected. His psittacosis/L.G.V. titre was 1 in 64, falling to 1 in 16 two weeks later.

Case 4.-A daughter of Case 2 had a similar illness with a positive titre of 1 in 256 .

Case 3 had an outside aviary of budgerigars, one of which had recently become ill. His flock was sacrificed and psittacosis virus was successfully grown from some of the birds. This family lived some miles from Case 1 in an outlying village and the two avian sources appeared to be quite independent.

During the period March to May a further series of patients with a clinical diagnosis of virus pneumonia and serological evidence of psittacosis/L.G.V. infection were seen at the clinic. During the summer months the numbers seen tailed off abruptly and none occurred in October or November. One isolated case occurred in December.

A total of 29 serologically proved cases were seen during the year, and the main symptoms, clinical and radiological features, and laboratory findings are given below.

We successfully traced an avian source in only two further cases, though avian contacts were noted in 15 of the 29 cases.

Case 9.-A boy aged 10 developed a fever, sore throat, and cough in August. His practitioner gave him a five-day course of chlortetracycline to which he appeared to respond. However, he continued to run an evening fever of $99-100^{\circ} \mathrm{F}$. $\left(37.2-37.8^{\circ} \mathrm{C}\right.$.) for several weeks, and he was therefore referred to the chest clinic. There were no abnormal signs on examination, and the chest film was clear. However, the psittacosis/L.G.V. titre was positive 1 in 256 , and after a further course of tetracycline he became afebrile. Serum from his pet budgerigar showed a positive titre of 1 in 64, with a trace at 1 in 128 , and this bird was regarded as the source of his infection.

Case 11.-A pet-shop owner became severely ill in December with fever, headache, aching muscles, and delirium. He was admitted to hospital, where he was found to have an impaired percussion note at his left base, a palpable spleen, and albuminuria. His chest film showed bronchopneumonic changes in the posterior segment of the left lower lobe. He was treated immediately with tetracycline, with a good response. The psittacosis/L.G.V. titre was less than 1 in 8 at the onset of his illness, but rose to 1 in 64 three weeks later. psittacosis virus was isolated from the spleen of a budgerigar which had died in his shop.

\section{Clinical Features and Radiological Changes}

With the exception of Case 11, none of the patients was severely ill. A diagnosis of pneumonia had often been made by their practitioners. Cough and fever were almost constant findings. Sputum was scanty and mucoid or mucopurulent. Aching muscles, sore throat, headache, chest pain, and dyspnoea occurred less frequently. There was haemoptysis in three 
cases. Physical signs in the chest were often scanty or absent, and frequently consisted of basal crepitations on one or other side. A relative bradycardia was noted occasionally. The white count and differential were usually normal, though the E.S.R. was invariably raised.

In five of the cases in this outbreak erythema nodosum occurred. This feature has not previously been noted in ornithosis. Details are given elsewhere (Sarner and Wilson, 1965).

Radiological changes were noted in about half the cases. The typical $x$-ray appearance was of homogeneous "ground-glass" opacity, which often contained small areas of radiolucency. Occasionally lobar or segmental consolidation or collapse occurred.

Resolution of the $x$-ray shadows was often delayed for some weeks after clinical cure. The interval between the first abnormal chest film and complete radiological clearing varied from one to twenty weeks, with an average interval of six weeks. This finding agrees with the experience of other authors (Stenstrom, Jansson, and Wager, 1962).

\section{Diagnosis}

The organism may be grown from sputum, throat washings, or blood, or from lungs and spleen after death (Westwood, 1963). Culture of the organism from these sources is not, however, possible if tetracyclines have previously been given. In fact over two-thirds of our cases had already received tetracycline from their practitioners and the complementfixation test was the only practical way of establishing the diagnosis. Various criteria have been suggested for serological diagnosis, including a rise to a high level followed by a fall, a fourfold rise or fall, and any titre above 1 in 60 (Stenstrom et al., 1962). We have taken a titre of 1 in 64 as evidence of recent infection. Twenty-one of our cases had positive titres in a dilution of 1 in 128 to 1 in 1,024 at some stage, and a rising or falling titre was demonstrated in 13.

\section{Discussion}

The psittacosis/L.G.V. group has been included in the range of routine virus complement-fixation tests on serum submitted to the Public Health Laboratory in Cambridge since 1958. Serum samples submitted showing a raised titre averaged two to three a year until 1964, when 61 samples were positive.

It therefore seems clear that an epidemic of ornithosis occurred in the Cambridge area in 1964. Although only 29 cases were seen at our centre, it seems likely that these represented a small proportion of the total. Because the disease was generally mild and responded well to treatment with tetracycline, many patients would therefore have been treated successfully by their family doctors without reference to the clinic.

In only half of the cases had there been any known contact with birds, and in only six was an avian source proved.
Human-to-human transmission could have occurred in two instances; Cases 16 and 29 were husband and wife, and there had been no avian contact. Case 22 had contact with Case 3 in so far as he delivered her bread. She had not had any known avian contact. No source of infection was discovered in any of the remaining cases and the origin of the epidemic remains obscure.

The infecting organism is resistant to drying and will remain viable for at least one month at normal temperatures (Meyer, 1959). Desiccation of the excreta of diseased birds and the subsequent dissemination of infected dust could therefore occur, and it is possible that the human cases were a reflection of an epidemic among the wild-bird population.

Homing pigeons returning from afar tend to roost at nightfall in the vicinity of their loft before completing their journey home, and another possibility might be that a flock of infected pigeons belonging to our first patient had been spreading infection in the area in this way.

The present attack seems explosive, in contrast with the description by Grist and McLean (1964) of 35 cases of nonvenereal infection with psittacosis/L.G.V. group in Glasgow during a period of 14 years (averaging less than three a year). They found evidence of infection in over $50 \%$ of Glasgow pigeons. In their view this avian source did not appear to have caused an important amount of human disease, and they considered the possible acquisition of human infection from other animals-for example, domestic cats and dogs, and mice.

\section{Summary}

An outbreak of ornithosis is described during which 29 cases attended one centre.

The diagnosis was made on serological grounds.

No source of infection was found in 23 cases. The illness was traced to infected budgerigars in five cases and to a flock of infected pigeons in one case. Human-to-human transmission may have occurred in two cases.

We wish to thank Dr. J. Boissard and Dr. G. R. C. Nagington, of the Public Health Laboratory, Cambridge, who carried out complement-fixation tests on these cases and identified the virus from the avian sources.

\section{RBFERENCES}

Bedson, S. P., Western, G. T., and Simpson, S. L. (1930). Lancet, 1, 235.

Grist, N. R., and McLean, C. (1964). Brit. med. F., 2, 21.

Leachman, R. D., and Yow, E. M. (1958). Arch. intern. Med., 102, 537.

Meyer, K. F. (1959). In Diseases of Poultry, edited by H. E. Biester and L. H. Schwarte, 4th ed., p. 521. Iowa State Univ. Press,. Iowa, U.S.A Olson, B. J., and Larson, C. L. (1944). Publ. Hlth Rep. (Wash.), 59,

and Treuting, W. L. (1944). Ibid., 59, 1299.

Sarner, M., and Wilson, R. J. (1965). Brit. med. F., 2, 1469.

Stenstrom, R., Jansson, E., and Wager, O. (1962). Acta med. scand., $171,349$.

Westwood, J. C. N. (1953). Proc. roy. Soc. Med., 46, 814. (1963). Practitioner, 191, 610. 